\title{
SPEED SENSORLESS CONTROL OF AN IPMSM DRIVE BASED ON ACTIVE FLUX CONCEPT
}

\author{
A. A. Hassan, A. M. El-Sawy, Y. S. Mohamed, and E. G. \\ Shehata \\ aahsn@yahoo.comsawy1980@yhaoo.com emadgameil@yahoo.com \\ Electrical Eng. Dept., Faculty of Engineering, El -Minia Uni., Egypt
}

(Received December 24, 2010 Accepted January 16, 2011)

This paper investigates a novel direct torque control (DTC) for a sensorless interior permanent magnet synchronous motor (PMSM) based on a sliding mode technique (SMC). The speed and position of the interior PMSM are estimated online based on active flux concept. To overcome the large ripple content associated with the direct torque, a torquelflux sliding mode controller has been employed. Two integral surface functions are used to construct the sliding mode controller (SMC). The command voltage is estimated from the torque and flux errors based on the two switching functions. The idea of total sliding mode is used to eliminate the problem of reaching phase stability. The space vector modulation (SVM) is combined with the sliding mode controller to ensure minimum torque and flux ripples and provides high resolution voltage control. The proposed scheme has the advantages of simple implementation, and does not require an external signal injection. In addition, it combines the merits of the direct torque control, sliding mode controller, and space vector modulation beside the sensorless control.

Simulation works are carried out to demonstrate the ability of the proposed scheme at different operating conditions. The results confirm the high performance of the proposed scheme at standstill, low and high speeds including load disturbances and parameters variation.

KEYWORDS: Active flux concept - Speed sensorless control - Direct torque control - Sliding mode control - Space vector modulation.

\section{I- INTRODUCTION}

Today, permanent magnet synchronous motor (PMSM) receives a great attention for drive applications. In particular, an interior permanent magnet synchronous motor has high efficiency due to the capability of producing reluctance torque. Speed or position control of the IPMSM needs the knowledge of the rotor speed or rotor position. However, the speed sensors or encoders have several drawbacks such as reliability, machine size and drive cost [1-3].

Recently, the advancement in the field of digital signal processing encouraged researchers to investigate many methods for speed estimation. The popular algorithm depends on estimating the emf in a rotating reference frame [1-4]. This algorithm gives acceptable performance at medium and high speeds and fails at low speeds. Other 
algorithms estimate the motor speed using the stator inductance variation with the rotor position [5-7]. Although these algorithms give a good performance at low speed and standstill operation it requires high frequency signal injection, which increases the drive complexity. In addition, a negative torque may be generated and thereby degrades the motor performance.

\begin{tabular}{|llll|}
\hline \multicolumn{3}{c|}{ NOMENCLATURE } \\
$i_{a b c}$ & Three phase stator currents & $V^{*}$ & Reference voltage amplitude \\
$i_{\alpha}, i_{\beta}$ & Stationary axes current components & Greek Symbols \\
$L_{q}$ & q-axis stator inductance & $\delta$ & Load angle \\
$L_{d}$ & d-axis stator inductance & $\phi_{\alpha}, \phi_{\beta}$ & Stationary axes stator flux \\
$p$ & Differential operator & $\hat{\phi}_{s}$ & Estimated stator flux amplitude \\
$P$ & Number of pole pairs & $\phi_{f}$ & Permanent magnet flux \\
$R_{s}$ & Stator resistance & $\gamma$ & Voltage vector angle with respect \\
$S_{a b c}$ & Switching state of the inverter & $\theta_{a}$ & to d-axis \\
$T_{e}$ & Electromagnetic torque & $\omega_{r}^{*}$ & (active flux position) \\
$v_{a b c}$ & Three phase stator voltages & $\omega_{r}$ & Actual rotor speed \\
$v_{\alpha}, v_{\beta}$ & Stationary axes voltage components & $\hat{\omega}_{r}$ & Estimated rotor speed \\
$V_{d}^{*} V_{q}^{*}$ & Reference voltage in synchronous & $\omega_{e}$ & Electric angular rotor speed \\
\hline
\end{tabular}

Speed observers have been employed also in many literatures. Sliding mode observer is used to estimate the motor speed or position based on the estimated flux [811]. However, the chattering phenomenon, and the need for high frequency signal injection are the drawbacks of this method. Also, extended Kalman filter [12-14] is employed to estimate the speed of the IPMSM using measured voltage and current signals. However, large computational burden is considered the main disadvantage of this technique. In [15], a linear model of the IPMSM based on the stationary reference frame is constructed. Then, a speed/position observer is designed based on the $\gamma$ positive real problem. However, large speed error appears at rated value. In addition, the sensorless control at low speed under load torque disturbance can not be realized successfully. In [16], a new observer is constructed based on multirate time system which estimates the applied voltage on the motor. In addition, a full order observer is used to estimate the stator flux and therefore the rotor position. However, this algorithm can not be applied at zero speed. In [17], an observer based on the motor model is used to estimate the rotor flux and the motor speed of the induction motor. This method is sensitive to the parameters variation.

In some literatures the induction motor speed is estimated from the stator flux, speed and either the load torque angle as in [18] or the slip speed as in [19]. However, 
the speed error is significant especially at low speed under load disturbance. Also, the motor parameters must be known accurately. Active flux concept [20] is used also for speed estimation. This method has the advantages of obtaining wide range of speed control without any signal injection. In addition, it uses a simple algorithm.

In this paper, the merits of the DTC together with the SMC are combined to control the IPMSM. Also, the active flux concept is employed to estimate the motor speed online. A torque/flux SMC combined with SVM are used to replace the hysteresis comparators and look up table of the classical DTC. The total sliding mode idea is used to design the SMC to eliminate the phase stability problem. The proposed scheme does not require additional complicated algorithms or signal injection schemes at very low speed. Computer simulations are carried out to evaluate the performance of the proposed scheme. The results show the superiority of the proposed scheme at different operating conditions.

\section{MATHEMATICAL MODEL OF IPMSM}

The mathematical voltage model of an IPMSM in the synchronous rotating frame is given by [14]

$p[x]=f(x)+g(x) u$

Where

$$
\begin{aligned}
& x=\left(\begin{array}{ll}
\phi_{q} & \phi_{d}
\end{array}\right)^{T}, \quad u=\left(\begin{array}{ll}
V_{q} & V_{d}
\end{array}\right)^{T}, \quad g(x)=\left[\begin{array}{ll}
1 & 0 \\
0 & 1
\end{array}\right], \quad \text { and } \\
& f(x)=\left[\begin{array}{l}
f_{1} \\
f_{2}
\end{array}\right]=\left[\begin{array}{c}
-\frac{R_{s}}{L_{q}} \phi_{q}-\omega_{e} \phi_{d} \\
-\frac{R_{s}}{L_{d}}\left(\phi_{d}-\phi_{f}\right)+\omega_{e} \phi_{q}
\end{array}\right] .
\end{aligned}
$$

The stator flux components can be estimated from the current model of the IPMSM in the synchronous frame as follows:

$\phi_{q}=L_{q} i_{q}$

$\phi_{d}=L_{d} i_{d}+\phi_{f}$

\section{III- SPEED ESTIMATION OF THE IPMSM}

The concept of active flux (or torque producing flux) for the IPMSM is defined as follows [20]:

$\phi_{a}=\phi_{f}+\left(L_{d}-L_{q}\right) i_{d}$

The pervious equation indicates that the active flux vector is aligned with the d-axis of the rotor frame.

Using equations (3) and (4), one can obtain:

$\phi_{a}=\phi_{d}-L_{q} i_{d}$

Equation (2) can be rewritten as:

$0=\phi_{q}-L_{q} i_{q}$ 
Combining equations (5) and (6), the active flux can be described in the space phasor form as:

$$
\bar{\phi}_{a}=\bar{\phi}_{s}-L_{q} \bar{i}_{s}
$$

Where $\bar{\phi}_{a}, \bar{\phi}_{s}, \bar{i}_{s}$ are the active flux, stator flux and stator current space vectors respectively.

Substituting the stator flux in equation (7) by the integration of the back emf , the active flux becomes:

$$
\bar{\phi}_{a}=\int\left(\overline{V_{s}}-R_{s} \bar{i}_{s}\right) d t-L_{q} \bar{i}_{s}
$$

Equation (8) indicates that the active flux vector can be estimated using the stator voltage and current space vectors. The active flux can be expressed in the polar form as:

$\bar{\phi}_{a}=\phi_{a} \angle \theta_{a}$

Where $\phi_{a}$, and $\theta_{a}$ are the amplitude and angle of the active flux space vector. Since the active flux vector is aligned with the d-axis of the rotor frame, then the rotor position is estimated from:

$\theta_{a}=\tan ^{-1}\left(\frac{\phi_{\beta a}}{\phi_{\alpha a}}\right)$

Where $\phi_{\alpha a}$ and $\phi_{\beta a}$ are the components of the active flux in the stator frame.

The motor speed can be estimated from the time differentiation of equation (10) as:

$\hat{\omega}_{r}=\frac{d \theta_{a}}{d t}=\frac{\left(\phi_{\alpha a}\right)_{k-1} \cdot\left(\phi_{\beta a}\right)_{k}-\left(\phi_{\beta a}\right)_{k-1} \cdot\left(\phi_{\alpha a}\right)_{k}}{T_{s} \cdot\left[\left(\phi_{\alpha a}\right)_{k}^{2}+\left(\phi_{\beta a}\right)_{k}^{2}\right]}$

Where the active flux components are calculated at the samples $k$ and $k-1$, and $T_{s}$ is the sampling interval. A low pass filter may be used with the speed estimator to reduce the noise.

\section{DIRECT TORQUE CONTROL OF AN IPMSM}

Direct torque control is considered the simplest control technique of PMSM for industrial applications where torque control is desirable. For IPMSM, the torque equation can be written as [21-22]:

$T_{e}=\frac{3 P \phi_{s}}{4 L_{d} L_{q}}\left[2 \phi_{f} L_{q} \sin (\delta)-\phi_{s}\left(L_{q}-L_{d}\right) \sin (2 \delta)\right]$

The torque equation consists of two terms, the first term is the excitation torque and the second term is the reluctance torque. For constant stator flux amplitude, the torque can be controlled by controlling the load angle $(\delta)$. In other words, the torque can be controlled by controlling the stator flux speed with respect to the rotor speed. The stator flux components are estimated using the measured stator voltage components: 


$$
\begin{aligned}
& \phi_{\alpha}=\int\left(v_{\alpha}-R_{s} i_{\alpha}\right) d t \\
& \phi_{\beta}=\int\left(v_{\beta}-R_{s} i_{\beta}\right) d t
\end{aligned}
$$

Therefore, the stator flux amplitude is estimated from:

$$
\hat{\phi}_{s}=\left(\phi_{\alpha}{ }^{2}+\phi_{\beta}{ }^{2}\right)^{0.5}
$$

Also, the electromagnetic torque can be estimated using the stator current and voltage components:

$$
\hat{T}_{e}=1.5 P\left(i_{\beta} \phi_{\alpha}-i_{\alpha} \phi_{\beta}\right)
$$

In the classical DTC, the errors between the reference and the estimated values of torque and flux are fed to their band hysteresis comparators to give digital outputs. The outputs of the hysteresis controllers and the number of sector are fed to a lookup table which selects the switching procedure based on the inverter states. The inverter state does not change till the output of the hysteresis controller or the sector number changes. In turn, the inverter states changes slowly, especially, at low speed [23-24]. For speed control based on the DTC, a proportional- integral (PI) controller is used to generate the reference torque from the difference between the reference and measured speeds.

\section{DESIGN OF A TORQUE/ FLUX SMC}

The sliding mode strategy is based on the design of the discontinuous control signal that drives the system states toward special manifolds in state space. The manifolds are chosen in such a way that the system will have the desired behavior as the state converges to it. The principle of the DTC is the tracking of the electromagnetic torque by controlling the voltage input to the motor. The SMC is designed to generate the stator voltage command from the torque and flux errors. Two integral switching functions are used for torque and flux control. The stator voltage command is generated based on the two integral switching functions. The switching functions of the torque and flux are chosen as:

$$
\begin{aligned}
& s_{T}=K_{p} e_{T}+K_{i} \int_{0}^{t} e_{T} d t \\
& s_{\phi}=K_{p} e_{\phi}+K_{i} \int_{0}^{t} e_{\phi} d t
\end{aligned}
$$

where

$$
\begin{aligned}
& e_{T}=T_{e}{ }^{*}-\hat{T}_{e} \\
& e_{\phi}=\phi^{*}{ }_{s}-\hat{\phi}_{s}
\end{aligned}
$$

and $K_{p}, K_{i}$ are positive gains.

The stator flux linkage amplitude and the electromagnetic torque can be estimated respectively in the synchronous frame as follows:

$$
\begin{aligned}
& \hat{\phi}_{s}=\left(\phi_{d}{ }^{2}+\phi_{q}{ }^{2}\right)^{0.5} \\
& \hat{T}_{e}=K_{t}\left(\phi_{d} i_{q}-\phi_{q} i_{d}\right)
\end{aligned}
$$


Where $K_{t}=\frac{3}{2} P$

The task is to design a control law that drives the state trajectory to the intersection of the surfaces described earlier. The time differentiation of the sliding surfaces are:

$$
\begin{aligned}
& \dot{s}_{T}=K_{p} \dot{e}_{T}+K_{i} e_{T} \\
& \dot{s}_{\phi}=K_{p} \dot{e}_{\phi}+K_{i} e_{\phi}
\end{aligned}
$$

Combining equations (1-3), and (18-20) will yield:

$\dot{s}=M+F-D u$

Where

$$
\begin{aligned}
& \dot{s}=\left[\begin{array}{c}
\dot{s}_{T} \\
\dot{s}_{\phi}
\end{array}\right], \quad M=\left[\begin{array}{c}
M_{1} \\
M_{2}
\end{array}\right]=\left[\begin{array}{c}
K_{i} e_{T}+K_{p} \dot{T}^{*}{ }_{e} \\
K_{i} e_{\phi}+K_{p} \dot{\phi}^{*}
\end{array}\right], \quad F=\left[\begin{array}{c}
-K_{p} K_{t}\left(L \phi_{q} f_{1}+\left(L \phi_{d}+\frac{\phi_{f}}{L_{d}}\right) f_{2}\right. \\
-\frac{K_{p}}{\phi_{s}}\left(\phi_{d} f_{1}+\phi_{q} f_{2}\right)
\end{array}\right], \\
& D=\left[\begin{array}{cc}
K_{p} K_{t}\left(L \phi_{d}+\frac{\phi_{f}}{L_{q}}\right) & K_{p} K_{t} L \phi_{q} \\
\frac{K_{p}}{\phi_{s}} \phi_{q} & \frac{K_{p}}{\phi_{s}} \phi_{d}
\end{array}\right], \\
& u=\left(\begin{array}{ll}
V_{q} & V_{d}
\end{array}\right)^{T} \quad \text { and } \quad L=\frac{1}{L_{q}}-\frac{1}{L_{d}}
\end{aligned}
$$

Taking the uncertainties into account, equation (24) will become

$$
\dot{s}=M+F_{n}-D_{n} u+W
$$

Where $D_{n}, F_{n}$ are the nominal values of $D, F$.

and $W$ is the lumped uncertainty which can be expressed:

$W=\left[\begin{array}{l}W_{T} \\ W_{\phi}\end{array}\right]=\Delta F+\Delta D u$

follows:

Putting $\dot{s}=0$, the control effort law (reference voltage) can be obtained as

$u^{*}=V^{*}=D_{n}^{-1}\left(M+F_{n}+\alpha \operatorname{sign}(s)\right)$

where $\quad \alpha=\left(\begin{array}{cc}\alpha_{T} & 0 \\ 0 & \alpha_{\phi}\end{array}\right), \quad V^{*}=\left(\begin{array}{ll}V_{q}^{*} & \left.V_{d}^{*}\right)^{T}\end{array}\right.$

and $\alpha_{T}, \alpha_{\phi}$ are positive gains.

The stability of the proposed SMC is proved using Lyapunov stability theorem in the appendix.

The stator flux and the torque can be regulated by the stator voltage components. The highly nonlinear and coupled dynamics of the matrices $\left(D_{n}{ }^{-1}, F_{n}\right)$ complicate the design of the SMC. However, if the stator flux amplitude is controlled to be constant, the variables of the matrices $\left(D_{n}{ }^{-1}, F_{n}\right)$ can be analyzed as bounded disturbances regulating the stator flux and the torque. So, it can 
be added to the lumped uncertainties. The control effort equation can be written as follows:

$V^{*}=M+\alpha_{1} \operatorname{sign}(s)$

Where $\alpha_{1}>\left|W+D_{n}{ }^{-1} F_{n}\right|$

The control effort is designed in equation (26) such that the system trajectory is forced towards the sliding surface $s=0$. However, this control strategy produces some drawbacks associated with large control chattering that may wear coupled mechanisms and excite unstable system dynamics. In addition, the sensitivity of the controlled system to uncertainties still exists in the reaching phase. To overcome these problems, the total sliding mode control idea is chosen [25-26]. The control effort of the total torque/ flux SMC can be written as:

$V^{*}=M+\alpha_{1} \operatorname{sat}(s)+K_{c} s+\left[\begin{array}{c}K_{T} \hat{T}_{e} \\ K_{\phi} \hat{\phi}_{s}\end{array}\right]$

Where $\quad \operatorname{sat}(S)=\frac{S}{|S|+\lambda}, \quad$ and $\quad K_{T}, K_{\phi}, K_{c}$ and $\lambda$ are positive gains. The function $\operatorname{sat}(S)$ is used instead of the function $\operatorname{sign}(S)$ to reduce the chattering in the control effort.

The reference voltage amplitude and position are estimated as follows:

$V^{*}=\sqrt{V_{d}^{* 2}+V_{q}^{* 2}}$

$\gamma=\tan ^{-1}\left(\frac{V_{q}^{*}}{V_{d}^{*}}\right)$

As shown in figure (1), the reference voltage position with respect to $\alpha$-axis in a stationary frame is expressed as:

$\theta^{*}=\gamma+\theta_{a}$

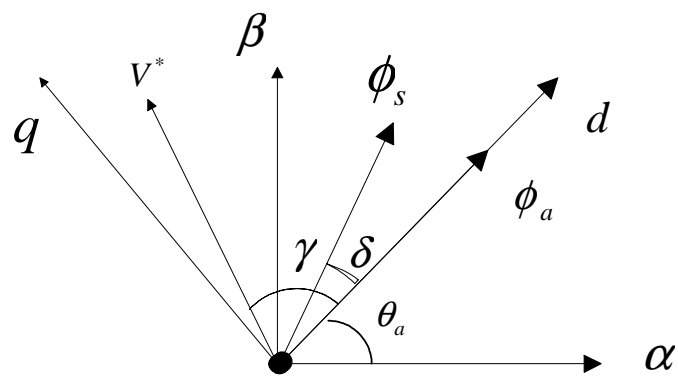

Fig.(1) Space position of the stator voltage and flux vectors.

\section{SPACE VECTOR MODULATION}

Although the SMC can provide high performance and low ripple content, the variable switching frequency problem is not overcome. The sinusoidal pulse width modulation can be combined with SMC to solve this problem but it has some drawbacks. Thus it is unable to fully utilize the dc voltage, and gives more total harmonic distortion. The 
SVM is preferred for DTC over PWM technique [27-28]. It is based on the space vector representation of the stator voltage in the $(\alpha, \beta)$ stationary frame. For two level inverters, there are eight states available for this vector according to eight switching positions as shown in figure (2). The SVM principle is based on the switching between two adjacent active vectors and two zero vectors during one switching period [28]. In order to reduce the number of switching actions and make full use of active turn-on time, the vector is commonly split into two nearest adjacent voltage vectors and zero vectors $V_{7}$ and $V_{0}$ in an arbitrary sector. For example, during one sampling interval, the stator voltage space vector in sector (I) can be expressed as:

$V^{*}=\frac{T_{0}}{T_{s}} V_{0}+\frac{T_{1}}{T_{s}} V_{1}+\frac{T_{2}}{T_{s}} V_{2}+\frac{T_{7}}{T_{s}} V_{7}$

where $\mathrm{T}_{\mathrm{S}}$ is the sampling time, and $\quad V_{1}=\sqrt{\frac{2}{3}} V d c$

$T_{s}-T_{1}-T_{2}=T_{0}+T_{7} \geq 0$

The required time period spending in each of the active and zero states are given by

$T_{1}=\frac{\left|V^{*}\right| \sin (\pi / 3-\theta)}{\left|V_{1}\right| \sin (2 \pi / 3)} T_{s}$

$T_{2}=\frac{\left|V^{*}\right| \sin (\theta)}{\left|V_{1}\right| \sin (2 \pi / 3)} T_{s}$

$T_{z}=T_{s}-T_{1}-T_{2}=T_{0}+T_{7}$

The pulse command signals pattern for the inverter for Sector I can be constructed as in Figure (3). For the sectors II-VI the same rules can be applied.

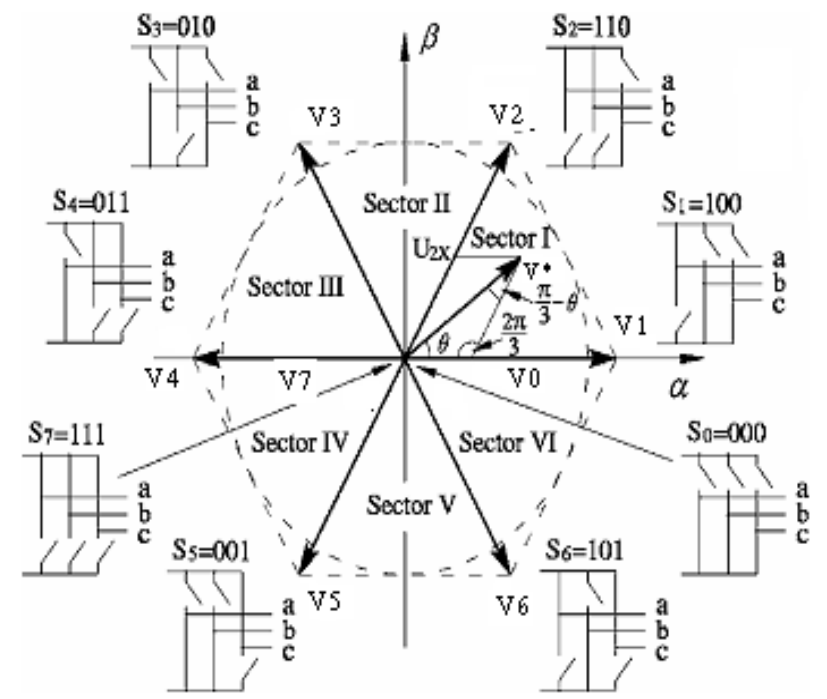

Fig. (2). Space voltage vectors of two level inverter. 


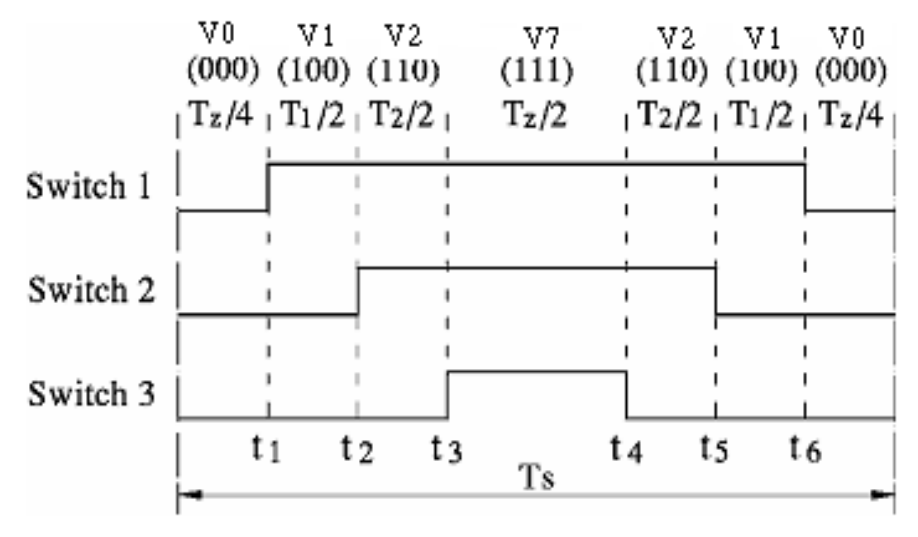

Fig.(3). Pulse command signal pattern of sector (I).

The block diagram of the speed sensorless torque/flux sliding mode controller of an IPMSM is shown in figure (4). The stator flux vector and the motor torque are estimated from the measured voltage and current signals (eqns. 12-13). The rotor position and speed are estimated from the active flux vector (eqns.10-11). The figure shows also that the SMC generates the stator reference voltage based on the torque and flux errors. No additional measurements or axis transformation are required. Space vector modulation is used to generate the inverter switching states with constant switching frequency. In a conventional DTC, a single voltage vector is applied during each sample period. When SVM is used, as shown in figure (3), six voltage vectors are applied during each sample. The number of switching states increases, and in turn, the torque and flux ripples decrease. Thus, the SVM provides high resolution output voltage. For speed control based DTC, a proportional- integral (PI) controller is used to develop the torque command for the SMC from the speed error.

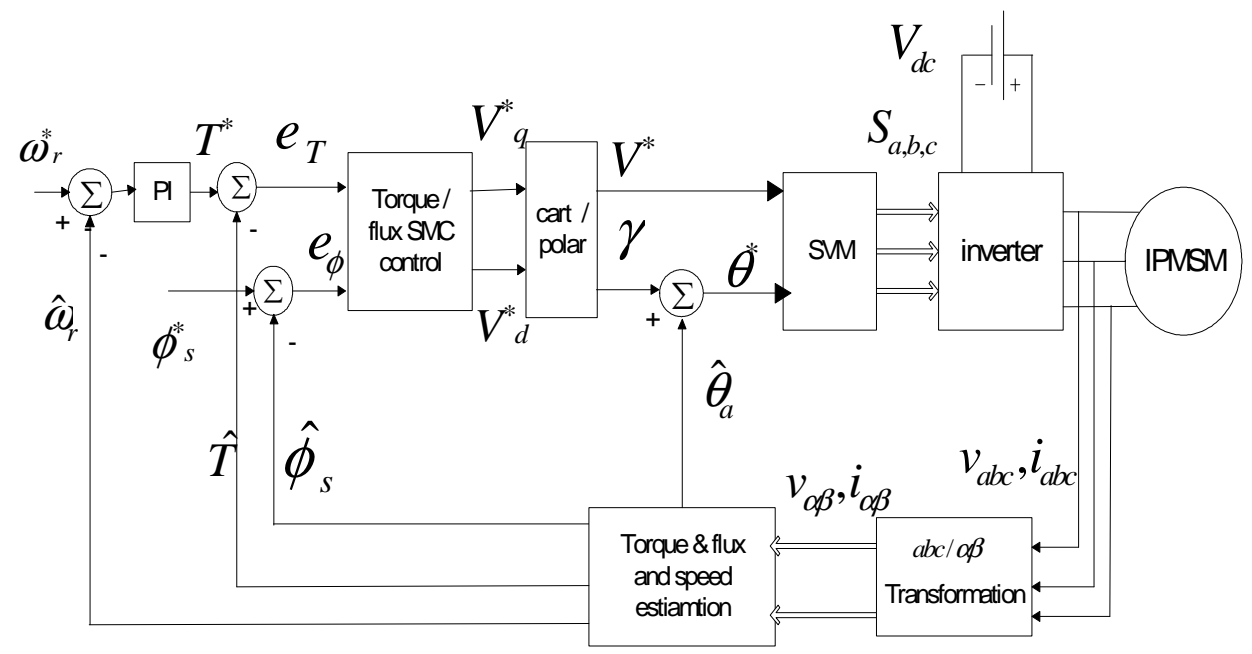

Fig.(4) Block diagram of the proposed sensorless sliding mode control scheme. 


\section{V- SIMULATION RESULTS}

Simulation works are carried out to evaluate the performance of the proposed scheme. The simulations are performed using the MATLAB/ Simulink simulation package. The parameters and data of the IPMSM used for simulation procedure are listed in table (1). The following settings are chosen for the control system:

Gains of the PI speed controller are selected as: $\mathrm{K}_{\mathrm{sp}}=0.01, \mathrm{~K}_{\mathrm{si}}=0.5$.

Switching frequency of SVM $=6 \mathrm{KHz}$.

Sampling time of speed estimator $=10 \mathrm{KHz}$.

The parameters of the torque/ flux sliding mode controller are selected as:

$$
K_{T}=K_{\phi}=100, K_{c w}=100, \alpha_{1}=\left[\begin{array}{ll}
200 & 200
\end{array}\right]^{T}, K_{p}=2, K_{i}=30 .
$$

Table (1) Parameters and data of the IPMSM

\begin{tabular}{|c|c|c|c|}
\hline No. of pole pairs & 2 & Base speed $\omega(\mathrm{rpm})$ & 1500 \\
\hline Rs $(\Omega)$ & 6 & Magnet flux linkage $\Phi_{\mathrm{f}}(\mathrm{Wb})$ & 0.337 \\
\hline Lq $(\mathrm{H})$ & 0.1024 & Rated torque Te (N.m) & 3 \\
\hline Ld $(\mathrm{H})$ & 0.0448 & Vdc (volt) & 300 \\
\hline
\end{tabular}

To evaluate the performance of the proposed scheme, the simulations are carried out at standstill, low and high speed operation with load disturbance and parameters variation.

\section{Case (1) Standstill operation:}

The motor is assumed to be operated at zero speed along the simulation period. The load torque is assumed to be $2 \mathrm{~N} . \mathrm{m}$ (66.6\% of rated torque) at starting and increased steeply to 4 N.m (133.3\%)at $\mathrm{t}=4 \mathrm{sec}$. The flux command is assumed to be fixed at 0.5 $\mathrm{Wb}$. The damping coefficient and the moment of inertia are detuned by $50 \%$. The simulation waveforms are shown in figure (5). The figure shows that the actual and estimated speeds are aligned. A speed dip occurs at the instant of load disturbance and recovered in less than 0.5 second. The figure depicts that the speed error between the actual and estimated is about $0.1 \mathrm{rpm}$ at steady state and $1 \mathrm{rpm}$ at load disturbance. As a result of using torque/flux SMC with space vector modulation, it is indicated that the ripples in the torque and flux waveforms are shown to be very low. The flux ripple is about $\pm 0.01 \mathrm{~Wb}(2 \%)$ and the torque ripple is \pm 0.07 N.m (3.5\%) at 2 N.m.

\section{Case (2) Low speed operation with load disturbance:}

In this case, the motor is assumed to be accelerated from zero to $100 \mathrm{rpm}$ in $0.5 \mathrm{sec}$. and kept constant at this value till $\mathrm{t}=4$ second. Then, the command speed is decreased steeply to $50 \mathrm{rpm}$. The flux command is assumed to be kept constant at $0.5 \mathrm{~Wb}$. The 
load torque is stepped from 2 to 3 N.m at $t=2 \mathrm{sec}$. As in the pervious case, the damping coefficient and the moment of inertia are assumed to be less than nominal by $50 \%$. The simulation waveforms are shown in figure (6). It is seen that the actual and estimated speeds can track the trajectory of the reference speed very well. The speed error is found to be less than $0.5 \%$ at $100 \mathrm{rpm}$. A small dip occurs in the estimated and actual speeds at the instant of load disturbance. The speed waveforms are enlarged at the instant of speed change to demonstrate the fast speed response of the proposed scheme. The figure shows that the torque and flux waveforms contain low ripples. The stator flux ripple is about $\pm 0.015 \mathrm{wb}( \pm 3 \%)$ and the torque ripple is $\pm 0.15 \mathrm{~N} . \mathrm{m}$ at 3 N.m (5\%). The torque waveform is enlarged to show that the system has fast torque dynamic response. Figure (7) illustrates that the actual and estimated rotor positions are aligned and there is no phase difference between them. The figure depicts also that the absolute error is nearly zero. Figure (8) shows the locus of the stator flux at 100 rpm in the stationary frame. It is noticed that the flux profile attains its circular shape very quickly. This means that the stator flux has fast transient response and its components are sinusoidal and displaced in phase by $90^{\circ}$.
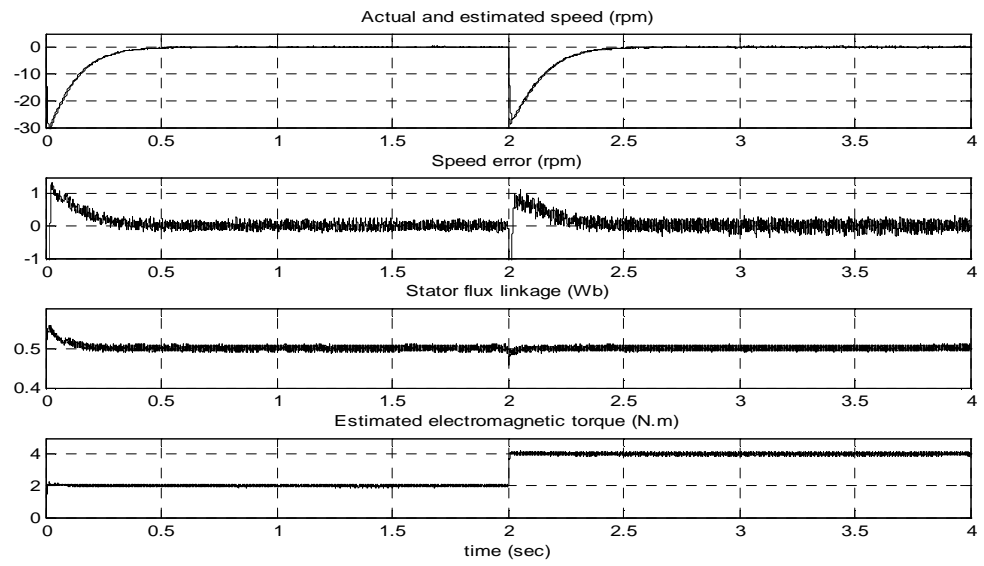

Fig. (5) Simulation output of the proposed scheme at standstill operation.
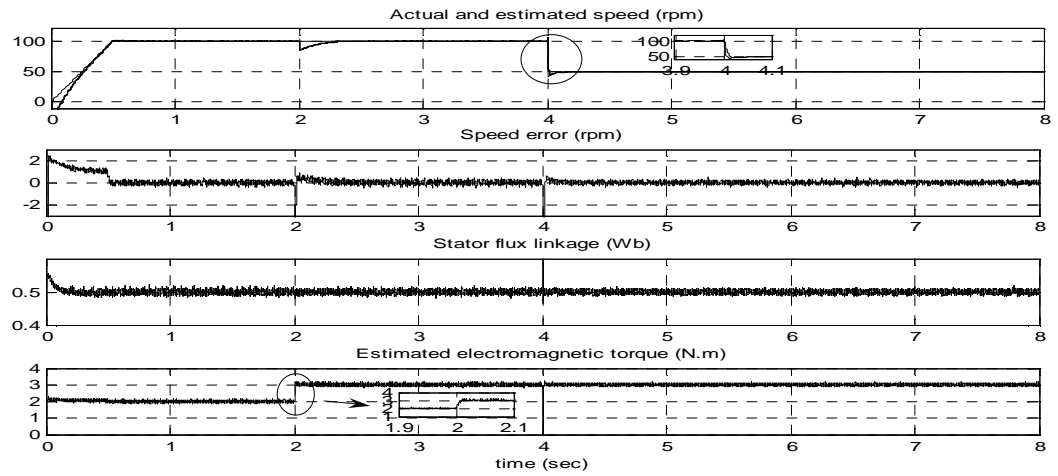

Fig. (6) Simulation waveforms at low speed (100 rpm). 

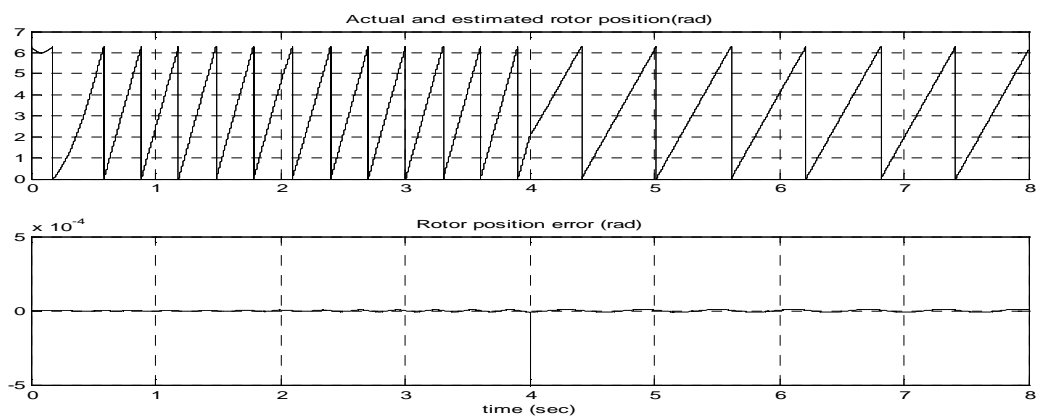

Fig. (7) Actual and estimated rotor position and their difference at 100rpm.

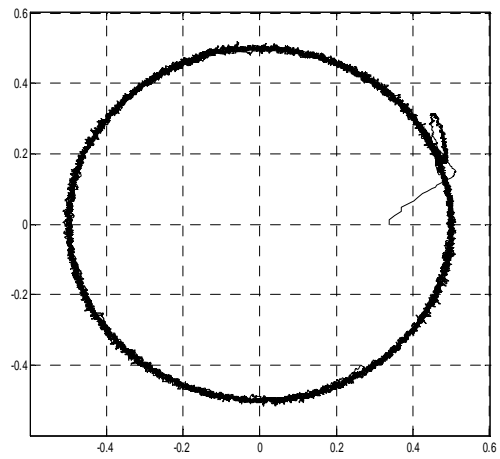

Fig.(8) Locus of the stator flux in the stationary reference frame at $100 \mathrm{rpm}$.

\section{Case (3) High speed operation:}

In this case, the performance of the proposed scheme is tested under high speed operation. The command speed is assumed to be increased from zero to $1500 \mathrm{rpm}$ in 1 second. The flux command is fixed at $0.5 \mathrm{~Wb}$. The load torque is increased from 2 to 3 N.m at $\mathrm{t}=3$ second. The stator resistance of the motor is assumed to be increased steeply by $50 \%$ at $\mathrm{t}=6$ second. The damping coefficient and the moment of inertia are increased by $100 \%$ at $\mathrm{t}=1$ second.

Figure (9) shows oscillations in the estimated speed waveforms. These oscillations can be reduced by selecting the appropriate cut-off frequency of the filter and the PI-speed controller gains. At steady state, the speed error is about $3 \mathrm{rpm}$ $( \pm 0.2 \%)$ which increases to $5 \mathrm{rpm}( \pm 0.33 \%)$ with the increase of the stator resistance. Also, the figure shows smooth torque and flux waveforms where, the stator flux ripple is about $\pm 0.03 \mathrm{wb}(6 \%)$ and the torque ripple is \pm 0.25 N.m at 3 N.m $(8.33 \%)$. 

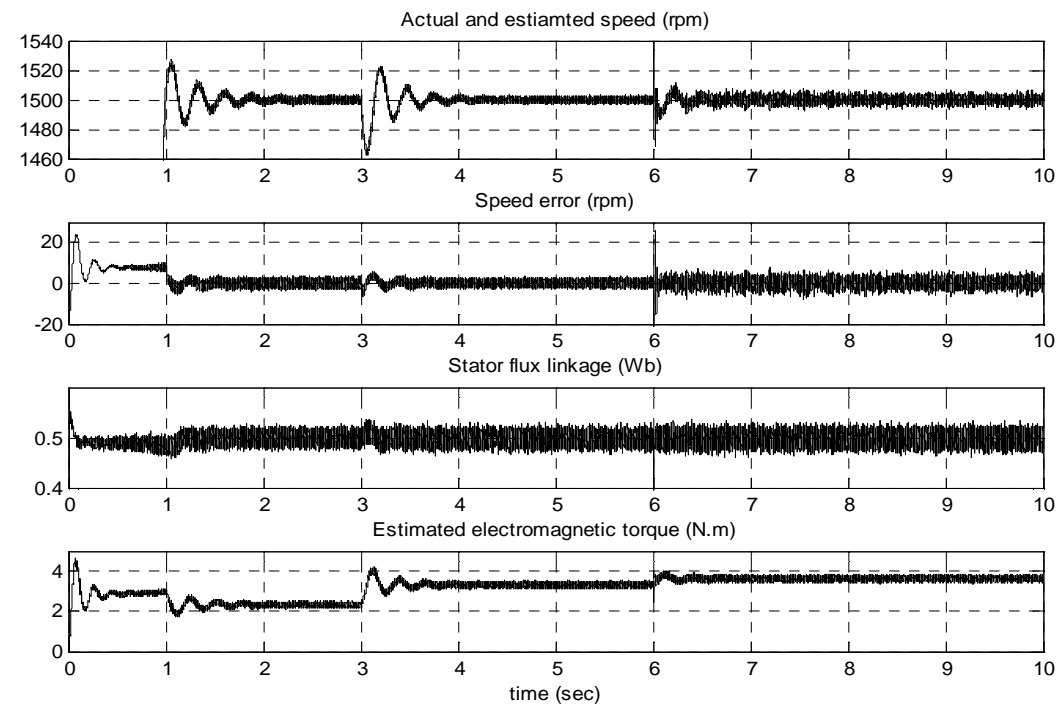

Fig. (9) Simulation waveforms at high speed operation.

\section{VI- CONCLUSION}

This paper presents the torque and flux control of the IPMSM based on the direct torque technique. Active flux concept is proposed to estimate the motor speed and position online. To solve the high ripple content problems associated with the classical DTC, a torque/ flux SMC is introduced in the DTC scheme. The SMC has been designed based on the torque and flux errors. The control law of the SMC is designed to reduce the chattering phenomenon and ensure reaching phase stability. Also, a SVM is used to provide constant switching frequency and reduces the ripple content. Simulation results demonstrate that the proposed scheme still preserve the fast dynamic response of the DTC. In addition, the system has good performance at all speeds including standstill and low speeds in the steady state. Also, the proposed scheme has high robustness against parameters variation and load disturbance.

\section{APPENDIX}

The stability of the proposed SMC can be proved using Lyapunov stability theorem.

Defining Lyapunov function as:

$V=\frac{1}{2} s^{T} s$

The time derivative of $\mathrm{V}$ on the state trajectory is given by

$\dot{V}=s^{T} \dot{s}$

Substituting equation (30) in equation (37), one can obtain:

$$
\dot{V}=s^{T} M+s^{T} F_{n}-s^{T} D_{n} u+s^{T} W
$$

Substituting the control effort from equation (29) into equation (38)

$\left.\dot{V}=s^{T} M+s^{T} F_{n}+s^{T} W-s^{T} M-s^{T} F_{n}-s^{T} \alpha_{1} \operatorname{sign}\left(s^{T}\right)\right)$ 
i.e $\quad \dot{V}=s^{T} W-\alpha_{1}\left|s^{T}\right|$

For $\alpha_{1}>|W|$, equation (40) will ensure $\dot{V} \leq 0$. This proves the stability of the proposed scheme.

\section{REFERENCES}

(1) Shigeo Morimotor, Keisuke Kawamoto, Masayuki Sanada and Yoji Takeda , Sensorless control strategy for salient pole PMSM based on extended EMF in rotating frame, IEEE Trans. Indust. Appl., Vol. 38, No. 4,p. 1054 (2002)

(2) Zhiqian Chen, Muyuwo Tomita, Shinji Doki, Shigeru Okuma, An extended electromotive forace model for sensorless control of interior permanent magnet synchronous motors, IEEE Trans. Indust Electron., Vol. 50, No. 2, p 288 (2003).

(3) Shinji Ichikawa, Muyuwo Tomita, Shinji Doki, Shigeru Okuma, Sensorless control of permanent magnet synchronous motors using online parameters identification based on system identification theory, IEEE Trans. Indust Electro., Vol. 53, No. 2, p. 363 (2006).

(4) Shigeo Morimotor, Masayuki Sanada and Yoji Takeda, Mechincal sensorless drives of IPMSM with online parameter identification, IEEE Trans. On Indust. Appl., Vol. 42, No. 5, p. 1241 (2006).

(5) Matthew J. Corley and Robert D. Lorenz, Rotor position and velocity estimation for a salient pole permanent magnet synchronous machine at standstill and high speeds, IEEE Trans. Indust. App., Vol. 34, No.4, p.784 (1998).

(6) Antti Piipo, Marko Iinkkanen, and Jorma Luomi, Adaptation of motor parameters in sensorless PMSM drives, IEEE Trans. Indust. Appl. Vol. 45, No. 1, p 203 (2009).

(7) Chan-Hee Choi and Jul-Ki Seok, Pulsating signal injection based axis switching sensorless control of surface mounted permanent magnet motors for minimal zero current clamping effects, IEEE Trans. Indust. Appl., Vol. 44, No. 6, p. 1741 (2008).

(8) Cristian Lascu, Ion Boldea and Frede Blaabjerg, Direct torque control of sensorless induction motor drives: a sliding-mode approach, IEEE Trans. Indust. Appl. Vol. 40, No. 2, p. 532 ( 2004).

(9) Gheorghe-Daniel Andreescu, Cristian Ilie Pitic, Frede Blaabjerg and Ion Boldea, Combined flux observer with signal injection enhancement for wide speed range sensorless direct torque control of IPMSM drives, IEEE Trans. Energy Convers, Vol. 23 No.2, p. 393 (2008).

(10) Gilbert Foo, and M. F. Rahman, Sensorless Sliding-Mode MTPA Control of an IPM Synchronous Motor Drive Using a Sliding-Mode Observer and HF Signal Injection, IEEE Trand. Indust. Electron, Vol. 57, No. 4,(2010)

(11) Zhiqian Chen, Muyuwo Tomita, Shinji Doki, Shigeru Okuma ,New adaptive sliding mode observers for position- and velocity-sensorless controls of brushless motors, IEEE Trans. Indust Electron., Vol. 47, No. 3, P. 582. (2000).

(12) Mohamed Boussak, Implementation and experimental investigation of sensorless speed control with initial rotor position estimation for interior permanent magnet synchronous motor drive, IEEE Trans. Indust Electron. Vol. 20, No. 6, p. 1413 (2005). 
(13) YongLiu, Zi Qiang Zhu and David Howe, Instantaneous torque estimation in sensorless direct-torque-controlled brushless DC motors, IEEE Trans. Indust. Appl., Vol. 42, No. 5, p. 1275 (2006).

(14) Zhuang Xu. and M.A. Rahman, An adaptive sliding stator flux observer for a direct-torque-controlled IPM synchronous motor drive, IEEE Trans. Indust Electron., Vol.54, No.5, p. 2398 (2007).

(15) Masaru Hasegawa and Keiju Matsui, IPMSM position sensorless drives using robust adaptive observer on stationary reference frame, IEEJ Trans Vol.3 , p. 120 (2008).

(16) Masaru Hasegawa, Satoshi Yoshioka and Keiju Matsui ,Position sensorless control of interior permanent magnet synchronous motors using unknown input observer for high speed drives, IEEE Trans. Indust. Appl., Vol. 45, No. 3, p. 938 (2009).

(17) Kyo-Beum Lee and Frede Blaabjerg, Sensorless DTC-SVM for induction motor driven by a matrix converter using a parameter estimation strategy, IEEE Trans. Indust Electron. Vol.55, No.2, p. 512(2008).

(18) M. F. Rahman, L. Zhong, Md.Enamul Haque and M.A. Rahman, A direct torquecontrolled interior permanent magnet synchronous motor drive without a speed sensor, IEEE Trans. Energy Convers. Vol.18, No.1, p. 17 (2003).

(19) Miran Rodic and Karel Jezernik, Speed-Sensorless sliding mode torque control of an induction motor, IEEE Trans. Indust Electron., Vol. 49, No. 1, p. 87 (2002).

(20) Ion Boldea, Mihaela Codruta Paicu, Gheorghe-Daniel Andreescu, and Frede Blaabjerg, "Active flux" DTFC-SVM sensorless control of IPMSM, IEEE Trans. Energy Convers. Vol. 24. No.2, p. 314 (2009).

(21) L. Zhong, M.F. Rahman, W.Y.Hu, K. W. Lim, and M.A.Rahman, A direct torque controller for permanent magnet synchronous motor drives, IEEE Trans. Energy Convers. Vol. 14, No. 3, p. 637 (1999).

(22) L. Zhong, M.F. Rahman, K. W. Lim, and L.Zhong, A direct torque controlled interior permanent magnet synchronous motor drive incorporating field weakening, IEEE Trans. Indust. Appl, Vol. 34, No.6, p.1246 (1998).

(23) L. Tang, M. F. Rahman, L. Zhong, , and Md.Enamul Haque, Problems associated with the direct torque control permanent magnet synchronous motor drive and their remedies, IEEE Trans. Indust. Electron.Vol.51,No. 4,p.799 (2004)

(24) Giuseppe S.Buja, Marian P.Kazmierkowski, Direct torque control of PWM inverter- fed ac machine- a survey, IEEE Trans. Indust. Electronic, Vol. 51, No. 4, p. 744 (2004).

(25) C. H. Fnag, C. H. Huang and S.K. Lin " Adaptive sliding-mode torque control of PM synchronous motor" IEE Proc. Power appl. Vol. 149, No. 3, p. 228-236 (2001).

(26) A. A. Hassan, Y. S. Mohamed, E. G. Shehata, Cascade sliding mode torque control of a permanent magnet synchronous motor, IEEE international conference on industrial technology, ICIT, p. 465 (2006).

(27) Tian-Jun Fu and Wen-Fang Xie, A novel sliding-mode control of induction motor using space vector modulation technique, The Instrumentation, Systems, and Automation Society (ISA) Transactions. Vol. 44, p. 481 (2005) 
(28) C. Lascu, I. Boldea, F. Blaabjerg, Variable -structure direct torque control - A class of fast and robust controllers for induction motor drives, IEEE Trans. Indust. Electron. Vol. 41, No.4, p. 785 (2004).

\section{التحكم فى سرعة محرك تزامنى ذى أقطاب مغناطيسية دائمة بلون جهاز استشعار بناء على مفهوم الفيض الفعال}

يقدم هذا البحث تحكما مباشـرا جديدا (Novel direct torque control) للمحرك التزامنى ذى

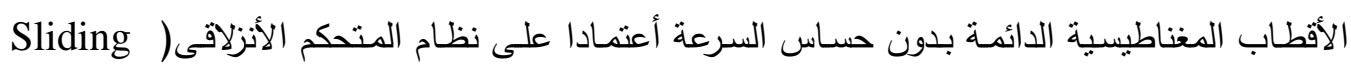
(mode controller

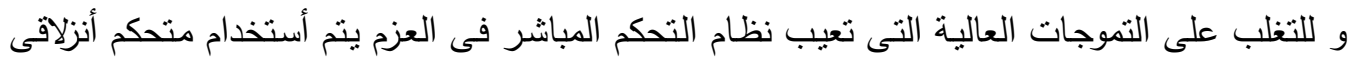

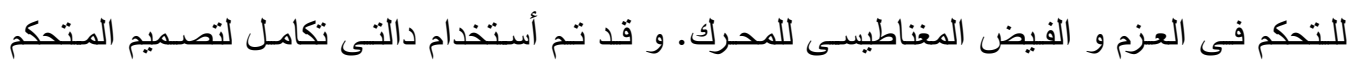
الأنزلاقى. حيث يقوم المتحكم بحساب الجهد من الفرق بين العزم المطلوب والعزم الفعلى و الفرق بين كثافة الفيض المغناطيسى و كثافة الفيض الفعلى اعتمادا على دالتى التكامل. و لضمان ثبانية النظام

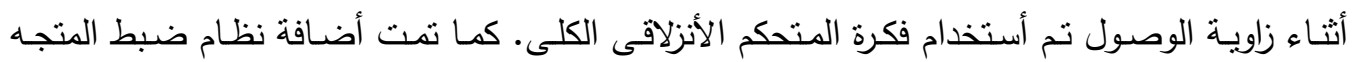
الفراغى (Space vector modulation) للحصول على أقل تموجات فى العزم و الفيض المغناطيسى للمحرك و زيادة نقاء موجة الجهد. يتميز النظام المقترح ببساطة و عدم الحاجة الى نظام حقن خارجى.

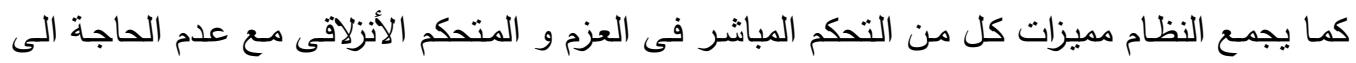

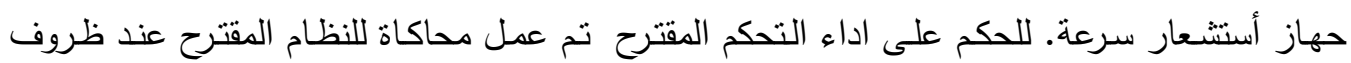

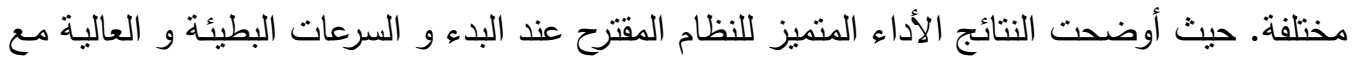
تغير معاملات المحرك او الحمل على المحرك. 